\title{
BMJ Open Cohort profile: Pacific Islands Families (PIF) growth study, Auckland, New Zealand
}

\author{
E Rush, ${ }^{1}$ M Oliver, ${ }^{2,3}$ L D Plank, ${ }^{4}$ S Taylor, ${ }^{2,3}$ L lusitini, ${ }^{3}$ S Jalili-Moghaddam, ${ }^{1}$ \\ F Savila, ${ }^{3} \mathrm{~J} \mathrm{Paterson}^{3} \mathrm{E}^{\mathrm{T}}$ Tautolo $^{3}$
}

To cite: Rush E, Oliver M, Plank LD, et al. Cohort profile: Pacific Islands Families (PIF) growth study, Auckland, New Zealand. BMJ Open 2016;6:e013407. doi:10.1136/bmjopen-2016013407

- Prepublication history for this paper is available online. To view these files please visit the journal online (http://dx.doi.org/10.1136/ bmjopen-2016-013407).

Received 9 July 2016 Revised 15 September 2016 Accepted 11 October 2016

CrossMark

For numbered affiliations see end of article.

Correspondence to

Professor E Rush;

elaine.rush@aut.ac.nz

\section{ABSTRACT}

Purpose: This article profiles a birth cohort of Pacific children participating in an observational prospective study and describes the study protocol used at ages 14-15 years to investigate how food and activity patterns, metabolic risk and family and built environment are related to rates of physical growth of Pacific children.

Participants: From 2000 to 2015, the Pacific Islands Families Study has followed, from birth, the growth and development of over 1000 Pacific children born in Auckland, New Zealand. In 2014, 931 (66\%) of the original cohort had field measures of body composition, blood pressure and glycated haemoglobin. A nested subsample $(n=204)$ was drawn by randomly selecting 10 males and 10 females from each decile of body weight. These participants had measurement of body composition by dual-energy $X$ ray absorptiometry, food frequency, 6 min walk test and accelerometer-determined physical activity and sedentary behaviours, and blood biomarkers for metabolic disease such as diabetes. Built environment variables were generated from individual addresses.

Findings to date: Compared to the Centres for Disease Control and Prevention (CDC) reference population with mean SD scores (SDS) of 0 , this cohort of 931 14-year-olds was taller, weighed more and had a higher body mass index (BMI) (mean SDS height $>0.6$, weight $>1.6$ and $\mathrm{BMI}>1.4$ ). 7 of 10 youth were overweight or obese. The nested-sampling frame achieved an even distribution by body weight.

Future plans: Cross-sectional relationships between body size, fatness and growth rate, food patterns, activity patterns, pubertal development, risks for diabetes and hypertension and the family and wider environment will be examined. In addition, analyses will investigate relationships with data collected earlier in the life course and measures of the cohort in the future. Understanding past and present influences on child growth and health will inform timely interventions to optimise future health and reduce inequalities for Pacific people.

\section{INTRODUCTION}

Pacific people are the fourth largest ethnic group in New Zealand (NZ), and the third

\section{Strengths and limitations of this study}

- This is the only adolescent cohort of Pacific Islands children followed from birth.

- This multifactorial study measures at age 14 years a diverse range of factors (food and sleep habits, physical activity and sedentary behaviour, and environmental factors) in relation to growth and physical development.

- Blood was sampled for the first time in the nested substudy for biomarkers of health and disease.

- This study has experienced high attrition of participants due primarily to high emigration from New Zealand.

largest group in Auckland, NZ's biggest city. ${ }^{1}$ The rate of population growth for Pacific people in NZ is approximately three times that of the general population. Estimates suggest a rise from $7.4 \%$ who identify with one or more Pacific ethnic groups in $2013^{1}$ to $10 \%$ in 2026 . This population is youthful and highly urbanised-almost half are aged $<20$ years, and over two-thirds reside in Auckland. Within the umbrella grouping of being 'Pacific', substantial diversity exists among Pacific communities in terms of language, heritage, ethnic affiliations and cultural practices. Pacific people, and in particular Pacific children and young people, have higher health risks and less healthy behaviours than other NZ people. ${ }^{2}$

With ageing, the prevalence of obesity and overweight increases, ${ }^{3}$ and from the 1980 s the rate of increase within a generation has also increased. For NZ Pacific people in 2015 , the prevalence of obesity was disproportionately high at $66 \%$ for adults and $30 \%$ for children, compared with $30 \%$ and $11 \%$ in the general population, respectively. ${ }^{2}$

The food and physical activity environment is recognised as having a strong effect on both physical activity and nutrition 
behaviours; however, until now almost all research in this field has been limited by cross-sectional design and a focus on adults or children only. Food insecurity, where food sometimes or often runs out due to lack of money, is associated with increased prevalence of obesity. ${ }^{4}$ In 2008/2009, the NZ Adult Nutrition Survey ${ }^{5}$ reported that food insecurity increased from 22\% of respondents in 1997 to $40 \%$, with $50 \%$ of Pacific women reporting food insecurity.

Adolescence represents a critical time of growth and puberty is marked from the first appearance of secondary sexual characteristics to full sexual maturation. ${ }^{6}$ Adolescence, a complex and interesting time, links childhood to adulthood. Patterns of growth and maturation during adolescence may be explained by previous life course events or help explain future risk for cardiometabolic health. ${ }^{7}$

The Pacific Islands Families (PIF) study provides a unique source of data for research on growth, development and psychosocial functioning at critical developmental stages within the family environment. In 2000 (at the time of the birth of their child), $40 \%$ of mothers in the longitudinal PIF study reported food insecurity. ${ }^{8}$ At 4 years, a positive association was observed between body size and consumption of protein and dairy foods, ${ }^{9}$ and at 6 years obesity $(27 \%)$ and overweight $(31 \%)$ prevalence were positively associated with birth weight. ${ }^{10}$ Another examination with this cohort showed that at 6 years (the transition to school), television watching and maternal waist circumference were associated with child body fatness, ${ }^{11}$ and physical activity (measured by an accelerometer) of the mother was positively associated with activity of her child. ${ }^{12}$

At age 14-15 years, we began a study to investigate the relationships of food and activity patterns, pubertal development and risks for diabetes and hypertension with body size; biomarkers for metabolic syndrome, liver function and inflammation; body fatness and growth rates; and individual, social and built environment factors associated with growth. This article describes the study protocol and presents preliminary descriptive results on body size and composition.

\section{COHORT DESCRIPTION}

From 2000 to 2015, the longitudinal PIF birth cohort study has followed the growth and development of 1398 Pacific children recruited following birth at Middlemore Hospital, South Auckland. This sample size was defined to enable findings to be generated that were specific to the predominant Pacific groups residing in NZ (Samoan, Tongan, Cook Islands Māori). Core measures include items on general health, child behaviour, relationships, acculturation and growth and development. Where specific priority social or health issues have arisen for Pacific peoples throughout the study, additional substudies have been conducted as appropriate. The last data collection wave occurred in 2011.

Between May 2014 and July 2015, informed consent was obtained from youth and their primary caregivers to participate in an assessment involving a series of physical measurements and a self-administered online questionnaire completed by the youth on a tablet computer with the assessor present to assist as necessary. A team of three assessors conducted the assessments in groups in secondary schools. Youth not able to be assessed at school were assessed at their home or other location convenient to them. Youth were thanked with a gift voucher for their participation. A total of 931 youth from the cohort were followed up. In cases where children exhibited metabolic risk (systolic blood pressure $>130 \mathrm{~mm} \mathrm{Hg}$ and/or glycated haemoglobin (HbAlc) $>40 \mathrm{mmol} / \mathrm{mol}$ ), parents were notified by telephone and by post and advised to take their child to their general practitioner for further tests. Thirty-two children were identified with HbAlc $>40 \mathrm{mmol} / \mathrm{mol}$ and only four had previously been diagnosed, one with type 1 diabetes. Where parental consent was obtained, measurements of concern were provided to the child's general practitioner.

At approximately the half-way point through data collection with the full cohort, a nested substudy started with a random selection from those youth who had already been measured in the full cohort assessment (up until that point), stratified by sex and body weight decile at 11 years. Youth selected in this way were visited by a Pacific research assistant and invited to participate in the substudy. Informed consent (separate to that for the full cohort assessment) was obtained from the parent and the youth who wished to participate and a food frequency and sleep habits questionnaire was administered at this time. Arrangements were made for the research assistant to transport the child to and from the Body Composition Laboratory of the University of Auckland, Department of Surgery, based at Auckland City Hospital. Children arrived at the laboratory in an overnight fasted state and at the completion of the assessment they were provided breakfast and thanked for their participation with a gift voucher. They were fitted with an ActiGraph accelerometer on an elasticated belt to be worn at the waist during waking hours over the next seven consecutive days, to be removed only during bathing, swimming or sleeping and playing contact sports (eg, rugby) and then transported back home or to school. On the eighth day, the accelerometer was collected from the youth's home by the research assistant. The target sample size was 10 participants in each stratum. Between October 2014 and February 2016, a total of 204 youth were assessed in the nested substudy.

For both the full cohort and the nested substudy assessments, parental consent was obtained to use the youth's current and historical home and school addresses in geographic information system analyses, for the purposes of assessing the child's physical and built environment.

\section{MEASUREMENTS}

The full cohort assessment included body size and composition (height (Seca 213 Hamburg, Germany), weight (Tanita BC545, Tokyo), waist and hip circumference 
with a non-stretchable tape and standing hand-to-foot bioimpedance analysis (ImpediMed Single Frequency $50 \mathrm{kHz}$ Bioimpedance Analyser, Imp-DF50; Impedimed, Brisbane, Queensland, Australia)), grip strength (Mentone, Melbourne), blood pressure using automated sphygmomanometers (Omron Auto Blood Pressure monitor T8;Omron Healthcare, Kyoto, Japan) with appropriate cuff sizes and a screening test for HbAlc (Afinion AS100 Analyser, Oslo, Norway), with a nonfasting finger prick blood sample of $1.5 \mu \mathrm{L}$. Validated questionnaires assessed physical activity and sedentary behaviours, ${ }^{13}$ food patterns ${ }^{14} 15$ and pubertal status. ${ }^{16}$

Body mass index (BMI) was calculated as weight in $\mathrm{kg}$ /height in metres squared and prevalence of obesity, overweight and thinness were derived, standardised for age and gender using the Cole cut-offs. ${ }^{17}$ The resistance measurements were multiplied by 1.028 to account for the standing position. ${ }^{18}$ Fat-free mass and percentage body fat were derived using the prediction equation validated previously with Pacific children and the same bioimpedance device. ${ }^{19}$

The substudy assessment included food frequency and sleeping times by online questionnaire and collection of a $15 \mathrm{~mL}$ fasting venous blood sample for biomarkers for metabolic syndrome (blood pressure, dyslipidaemia, glucose), liver function and inflammation. A further $5 \mathrm{~mL}$ of plasma was stored for future analysis of other non-communicable disease markers (where separate consent for this was obtained). Body composition analysis was by bioimpedance analysis as for the full study and by dual-energy X-ray absorptiometry (DXA, model iDXA, GE-Lunar, Madison, Wisconsin, USA) for total body and abdominal fatness and bone mineral content. Height, weight, waist circumference and blood pressure and resting pulse were measured. Anthropometric and blood pressure measurements for both the full cohort and substudy were repeated until within a predetermined tolerance (weight $\pm 0.5 \mathrm{~kg}$, height and waist $\pm 0.5 \mathrm{~cm}$ and bioimpedance $\pm 5 \Omega$, systolic and diastolic blood pressure $\pm 10 \mathrm{~mm} \mathrm{Hg}$ ). After screening with the Physical Activity Readiness Questionnaire, physical function and fitness were measured with the standard 6-min walk test ${ }^{20}$ and a grip strength test. ${ }^{21}{ }^{22}$ Physical activity was objectively assessed using GT3X+ ActiGraph accelerometers (Actigraph, Pensacola, Florida, USA). The reliability and validity of these accelerometers are well established. $^{23-25}$

Units were initialised using ActiLife 6 (Actigraph, Pensacola, Florida, USA), using a raw data sample frequency of $30 \mathrm{~Hz}$. Data were extracted into ActiLife as raw .gt3x files, and aggregated into .agd and .dat files using $15 \mathrm{~s}$ epochs and all download options checked (ie, steps, lux, inclinometer, low frequency extension enabled). Files were then converted to .csv within Meterplus (Santech, San Diego, California, USA). Downloaded data were screened on a weekly basis to identify any obvious accelerometer malfunctions or outliers. ${ }^{26}$ Accelerometer count thresholds of Evenson et $a l^{27}$ were employed to classify time spent sedentary, and in light, moderate and vigorous intensity physical activity (sedentary 0-25 counts $15 \mathrm{~s} /$, light 26-573 counts $15 \mathrm{~s} /$, moderate 574-1002 counts $15 \mathrm{~s} /$, vigorous $\geq 1003$ counts $15 \mathrm{~s} /$ ). ${ }^{27}$ Non-wear time was classified as $60 \mathrm{~min}$ or more of consecutive zero counts. ${ }^{28}$ Criteria for valid days were at least 7 hours of data; participants with three or more valid days will be included in analyses (Paper under consideration).

\section{Built environment}

Objective built environment measures will be calculated in ArcGIS V.10.2 (ESRI, Redlands, California, USA), as detailed below. Variables were calculated around individual residential addresses and school locations using three street network buffers (400, 800 and $1200 \mathrm{~m}$ ). This range of buffer sizes was employed to facilitate adaptability in the light of future emerging research and flexibility for differing research questions. ${ }^{29} 30$

\section{Walkability}

Drawing on the work of Frank et $a l^{31}$ three individual walkability components were derived around individual residential addresses: (1) Net residential density, the ratio of residential dwellings to the residential land area, (2) Street network connectivity, the ratio of number of intersections with three or more intersecting streets per square kilometre to land area and (3) Land use mix, an entropy index based on the presence or absence of five types of land use.

Accessibility to destinations: in the neighbourhood (eg, shops, doctor) was assessed using the Neighbourhood

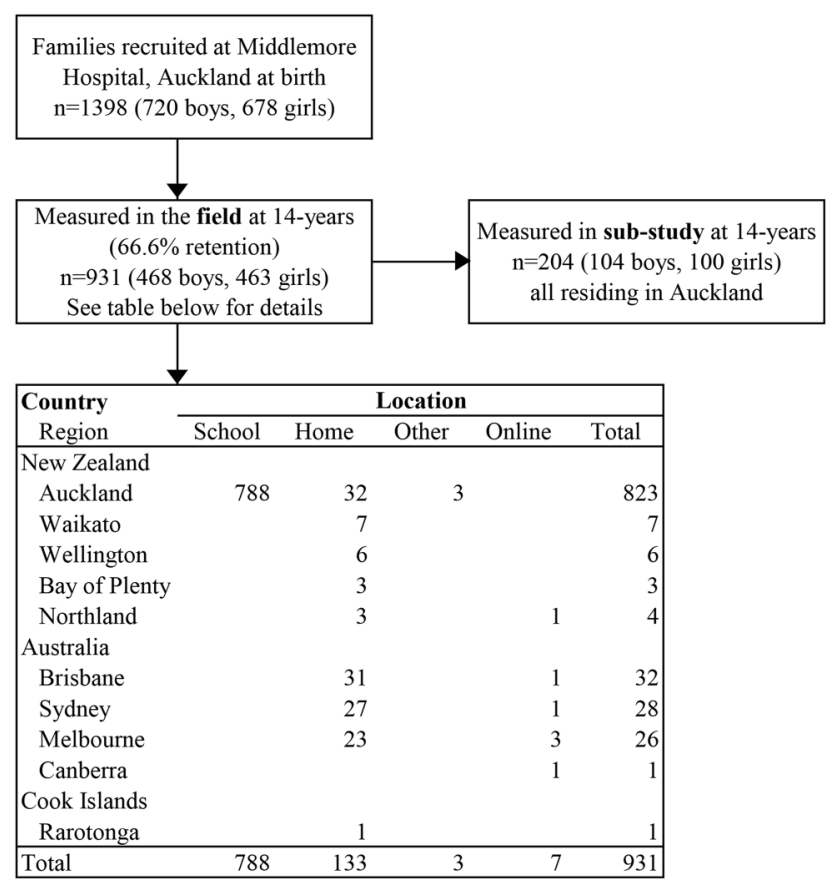

Figure 1 Consort style diagram of recruitment and retention by gender and location at 14 years. 
Destination Accessibility Index around individual addresses. $^{32} 33$

Availability of public open space: was determined by calculating the ratio of green space, including parks and playgrounds, that can be freely accessed by the public to the defined area for each individual address. ${ }^{34}$

Accessibility to green and blue spaces: was derived by calculating the shortest street network distance from each individual's home address to the nearest green space and to the nearest blue space (eg, waterways, rivers, coastline).

\section{Route to school}

(1) Distance to school was calculated using the shortest street network distance from home to school and (2) Steepness of the route to school was assessed, and the percentage of school route segments with a slope exceeding $5 \%$ calculated.

Pedestrian network connectivity: was calculated around both the home and the school using the ratio of the pedestrian network area to the maximum possible area within the defined boundary. ${ }^{35}$

Traffic speeds exposure: around both the home and school was assessed using road hierarchy as a proxy. The total lengths of all higher speed roads ( $\geq 60 \mathrm{~km} /$ hour) and all lower speed roads $(<60 \mathrm{~km} /$ hour $)$ were calculated within the defined boundary. Thereafter the ratio of high to low speed roads was calculated.

\section{DATA ANALYSIS}

Both the physical measurements data and the questionnaire data for the full cohort and substudy were entered into SurveyMonkey (with validation rules applied) and exported as SPSS (V.22, IBM) files. The SPSS files were restructured and cleaned. Descriptive statistics were calculated from the cleaned data sets, including means and SDs for numeric measurements and percentages for categorical variables.

\section{FINDINGS TO DATE}

For the full cohort study conducted between May 2014 and July 2015, retention was $66 \%$ of the original birth cohort. Of the 931 children seen, 788 were assessed at school, 133 were assessed at home and 10 who were not able to be physically seen completed the questionnaire part of the assessment via an online survey (figure 1). Of the 140 children assessed at home or online, 87 were assessed in Australia where they lived. Relocation to areas other than Auckland had occurred for $12 \%$ of children

Table 1 From 2000 to 2015, age and number of participants measured for variables associated with physical growth and risk for future disease

\begin{tabular}{|c|c|c|c|c|c|c|c|}
\hline $\begin{array}{l}\text { Year } \\
\text { Age } \\
\text { Measure of child } \\
\end{array}$ & $\begin{array}{l}2000 \\
\text { Birth }\end{array}$ & $\begin{array}{l}2004 \\
4 \text { years }\end{array}$ & $\begin{array}{l}2006 \\
6 \text { years }\end{array}$ & $\begin{array}{l}2009 \\
9 \text { years }\end{array}$ & $\begin{array}{l}2011 \\
11 \text { years } \\
\end{array}$ & $\begin{array}{l}2014 \\
14 \text { years } \\
\text { Full cohort }\end{array}$ & $\begin{array}{l}2015 \\
14 \text { years } \\
\text { Substudy }\end{array}$ \\
\hline \multicolumn{8}{|l|}{ Anthropometry/physical development/growth } \\
\hline Weight & 1379 & 895 & 895 & 885 & 949 & 917 & 204 \\
\hline Height & & 885 & 895 & 890 & 949 & 918 & 204 \\
\hline Waist circumference & & 896 & 895 & 891 & & 918 & 204 \\
\hline Pubertal development & & & & $949^{*}$ & $1007^{*}$ & 890 & \\
\hline Body fat by bioimpedance analysis & & 726 & 849 & 833 & & 900 & 204 \\
\hline Body fat by DXA & & & & & & & 204 \\
\hline \multicolumn{8}{|l|}{ Food patterns } \\
\hline Food frequency & & 907 & 801 & & & & 204 \\
\hline Dietary habits & & & & $976^{\star}$ & & 898 & \\
\hline \multicolumn{8}{|l|}{ Physical function } \\
\hline Subjective physical activity & & 901 & & & & 779 & \\
\hline Objective physical activity (by accelerometer) & & & & & & & 204 \\
\hline Objective fitness (by 6 min walk test) & & & & & & & 203 \\
\hline Grip strength & & & & & & 915 & 203 \\
\hline \multicolumn{8}{|l|}{ Geographical environment } \\
\hline Physical address of participants & 1398 & 909 & 897 & 891 & 952 & 934 & 204 \\
\hline \multicolumn{8}{|l|}{ Metabolic risk } \\
\hline Blood pressure, heart rate & & & 895 & 856 & & 914 & 204 \\
\hline $\mathrm{HbA} 1 \mathrm{c}$ point of care screening & & & & & & 768 & 202 \\
\hline \multicolumn{8}{|l|}{ Venepuncture } \\
\hline Fasting glucose, $\mathrm{HbA1c}$, insulin & & & & & & & 204 \\
\hline Fasting lipids, uric acid & & & & & & & 204 \\
\hline Liver function and satiety hormones & & & & & & & 204 \\
\hline Inflammation CRP & & & & & & & 204 \\
\hline
\end{tabular}

*Parent-reported.

CRP, C reactive protein; DXA, dual-energy X-ray absorptiometry; HbA1c, glycated haemoglobin. 
Table 2 Physical characteristics of youth at 14 years in full cohort and subsample

\begin{tabular}{|c|c|c|c|c|c|c|c|}
\hline & \multicolumn{2}{|l|}{ Full cohort } & \multicolumn{5}{|c|}{ Nested subsample } \\
\hline & \multirow[b]{2}{*}{$\begin{array}{l}\text { Boys } \\
(n=468)\end{array}$} & \multirow[b]{2}{*}{$\begin{array}{l}\text { Girls } \\
(n=463)\end{array}$} & \multicolumn{2}{|c|}{ At time of full study } & \multirow[b]{2}{*}{$\begin{array}{l}\text { p } \\
\text { Value* }\end{array}$} & \multicolumn{2}{|c|}{$\begin{array}{l}\text { At time of substudy } \\
\text { assessment }\end{array}$} \\
\hline & & & $\begin{array}{l}\text { Boys } \\
(n=104)\end{array}$ & $\begin{array}{l}\text { Girls } \\
(n=100)\end{array}$ & & $\begin{array}{l}\text { Boys } \\
(n=104)\end{array}$ & $\begin{array}{l}\text { Girls } \\
(n=100)\end{array}$ \\
\hline Age, years & $14.3(0.43)$ & $14.3(0.41)$ & $13.9(0.22)$ & $14.0(0.25)$ & & $14.9(0.43)$ & $14.9(0.47)$ \\
\hline \multicolumn{8}{|l|}{ Anthropometry } \\
\hline Weight, kg & $81.9(23.42)$ & 78.2 (19.13) & 77.9 (22.38) & $77.1(19.55)$ & 0.842 & $85.8(25.20)$ & $81.3(20.56)$ \\
\hline Height, cm & $171.6(7.56)$ & $165.1(6.10)$ & $170.1(7.63)$ & $164.5(5.58)$ & 0.573 & $175.4(7.12)$ & $166.6(5.58)$ \\
\hline Waist, cm & $87.0(16.13)$ & $80.7(12.55)$ & $86.0(15.89)$ & 80.6 (12.59) & 0.659 & $88.7(18.85)$ & $84.6(16.20)$ \\
\hline $\mathrm{BMI}, \mathrm{kg} / \mathrm{m}^{2}$ & $27.6(6.87)$ & $28.6(6.38)$ & $26.7(6.65)$ & $28.4(6.37)$ & 0.929 & $27.8(7.51)$ & $29.2(6.53)$ \\
\hline CDC weight, SDS & $1.82(1.11)$ & $1.67(0.78)$ & $1.71(1.14)$ & $1.67(0.81)$ & 0.489 & $1.79(1.19)$ & $1.68(0.75)$ \\
\hline CDC height, SDS & $0.79(0.94)$ & $0.64(0.92)$ & $0.85(0.93)$ & $0.64(0.85)$ & 0.532 & $0.82(0.90)$ & $0.75(0.86)$ \\
\hline CDC BMI SDS & $1.51(0.91)$ & $1.56(0.71)$ & $1.42(0.92)$ & $1.55(0.73)$ & 0.530 & $1.42(1.02)$ & $1.55(0.70)$ \\
\hline \multicolumn{8}{|l|}{ †Prevalence \% } \\
\hline Underweight & 0.9 & 0.0 & 0.0 & 0.0 & & 0.0 & 0.0 \\
\hline Normal & 28.2 & 21.5 & 28.8 & 20.0 & & 28.8 & 24.0 \\
\hline Overweight & 28.0 & 36.0 & 35.6 & 38.0 & & 31.7 & 34.0 \\
\hline Obese & 43.0 & 42.4 & 35.6 & 42.0 & & 39.4 & 42.0 \\
\hline \multicolumn{8}{|l|}{ Blood pressure } \\
\hline Systolic, mm Hg & $122(10)$ & $117(10)$ & $120(10)$ & $117(10)$ & 0.921 & $124(11)$ & $118(9)$ \\
\hline Diastolic, mm Hg & $65(9)$ & $67(8)$ & $65.7(8)$ & $65(7)$ & 0.253 & $71(7)$ & $72(7)$ \\
\hline Pulse, bpm & $76(12)$ & 79 (12) & 77 (12) & 78 (10) & 0.711 & $70(10)$ & $72(9)$ \\
\hline \multicolumn{8}{|l|}{ Body Composition } \\
\hline $\begin{array}{l}\text { Percentage of BF by } \\
\text { BIA }\end{array}$ & $26.2(8.56)$ & $31.9(0.30)$ & $25.6(8.10)$ & $33.4(5.76)$ & 0.778 & $24.8(8.12)$ & $32.9(6.47)$ \\
\hline Total FM by BIA & $23.0(13.43)$ & $25.9(0.52)$ & $21.2(12.01)$ & $26.7(10.70)$ & 0.904 & $22.9(13.78)$ & $27.3(10.56)$ \\
\hline Total FFM by BIA & $58.9(11.73)$ & $52.5(0.46)$ & 56.7 (12.31) & $50.6(9.72)$ & 0.646 & $63.0(13.21)$ & $53.9(12.63)$ \\
\hline $\mathrm{HbA} 1 \mathrm{C}, \mathrm{mmol} / \mathrm{mol}$ & $36.0(2.87)$ & $36.3(5.12)$ & $35.7(3.51)$ & $36.6(7.63)$ & 0.521 & $36.5(3.75)$ & $36.9(6.38)$ \\
\hline
\end{tabular}

(108/931). For the nested substudy, 204 children living in South Auckland were assessed at the laboratory with an average measurement duration of $53 \mathrm{~min}$.

Measurements undertaken to understand physical growth build on relevant measures from previous years (table 1). The participants in the nested substudy (table 2) were not (statistically) significantly different to the full cohort in terms of their anthropometry, blood pressure, body composition and HbAlc. Compared with the CDC reference growth curves ${ }^{37}$ with mean SD scores (SDS) of 0 , this cohort of 14-year-olds was taller, weighed more and had a higher BMI (mean SDS height $>0.6$, weight $>1.6$ and BMI $>1.4$ ) (table 2). Seven of 10 youth were overweight or obese. The prevalence of obesity and overweight had increased from 2011 to 2014, less in boys $(65.5 \%$ to $66.4 \%)$ than in girls $(66.7 \%$ to $81.0 \%)$ according to International Obesity Taskforce grades.

\section{STRENGTHS AND LIMITATIONS}

Culturally specific longitudinal research is essential to identify antecedent factors for growth trajectories from birth to adolescence. ${ }^{38}$ Despite these research needs, Pacific youth are generally under-represented in physical activity and health research. Building on 14 years of family engagement, this is a ground-breaking epidemiologically robust cohort focusing on determining the pathways leading to successful adaptation as the youth and their families negotiate critical developmental transitions. Unique findings from this research can be used to drive effective policies and programmes that serve the needs of Pacific families, promote well-being and address social disparities. The generalisability of potential outcomes of PIF research to migrant populations in other countries is an important potential contribution to international research in health and related areas. The major limitation of this study is the high attrition rate due in part to the transience/migration of the cohort and the logistical difficulties and follow-up costs for those in other geographical areas.

Understanding past and present influences on child growth and health will inform timely interventions and policies to optimise future health and reduce inequalities for Pacific peoples.

Author affiliations

${ }^{1}$ Faculty of Health and Environmental Sciences, Child Health Research Centre, Auckland University of Technology, Auckland, New Zealand 
${ }^{2}$ Department of Epidemiology and Biostatistics, Faculty of Health and Environmental Science, Auckland University of Technology, Auckland, New Zealand

${ }^{3}$ Centre for Pacific Health and Development Research, School of Public Health and Psychosocial Studies, Auckland University of Technology, Auckland, New Zealand

${ }^{4}$ Department of Surgery, Faculty of Medical and Health Sciences, University of Auckland, Auckland, New Zealand

Acknowledgements The authors wish to acknowledge the participants and their families for their ongoing support and participation. They also sincerely thank Desmond Ryan and Wafa Elasheg for their tireless efforts with data collection and completion of the project.

Contributors ER, MO, LDP, ST and JP participated in the study design. ST, LI and ER performed the editing and analysis of data. ER, MO and LI drafted the manuscript. All authors revised the article and agree with the final version and findings.

Funding This study was funded by a grant from the Health Research Council of New Zealand (14-156).

Competing interests None declared.

Ethics approval Ethical approval for the full cohort study was obtained from the Southern Health and Disability Ethics Committee on 4 December 2013 (ref. 13/STH/159) and for the nested substudy from the Central Health and Disability Ethics Committee on 28 July 2014 (ref. 14/CEN/108).

Provenance and peer review Not commissioned; externally peer reviewed.

Data sharing statement Researchers can apply to obtain raw data from the director of the Pacific Islands Families Study, Dr El-Shadan Tautolo, dtautolo@aut.ac.nz.

Open Access This is an Open Access article distributed in accordance with the Creative Commons Attribution Non Commercial (CC BY-NC 4.0) license, which permits others to distribute, remix, adapt, build upon this work noncommercially, and license their derivative works on different terms, provided the original work is properly cited and the use is non-commercial. See: http:// creativecommons.org/licenses/by-nc/4.0/

\section{REFERENCES}

1. Statistics New Zealand. 2013 Census ethnic group profiles Secondary 2013 Census ethnic group profiles 2015. 2013. http:// www.stats.govt.nz/Census/2013-census/profile-and-summaryreports/ethnic-profiles.aspx

2. Ministry of Health. Annual update of key results 2014/15L: New Zealand Health Survey. Wellington: Ministry of Health, 2015.

3. Ministry of Health. Understanding excess body weight: New Zealand Health Survey. Wellington: Ministry of Health, 2015.

4. Rush E. Food security for Pacific Peoples in New Zealand. A report for the obesity action coalition. Wellington, New Zealand: Obesity Action Coalition, 2009.

5. University of Otago, Ministry of Health. A focus on nutrition: key findings of the 2008/09 New Zealand Adult Nutrition Survey. Wellington: Ministry of Health, 2011.

6. Cameron N, Demerath EW. Critical periods in human growth and their relationship to diseases of ageing. Am J Phys Anthropol 2002:45(Suppl 35):159-84.

7. Johnson W, Kuh D, Hardy R. A life course perspective on body size and cardio-metabolic health. A life course perspective on health trajectories and transitions. Springer, 2015:61-83.

8. Rush E, Puniani N, Snowling N, et al. Food security, selection, and healthy eating in a Pacific Community in Auckland New Zealand. Asia Pac J Clin Nutr 2007;16:448-54.

9. Rush E, Obolonkin VV, Paterson J. Food frequency informationrelationships to body composition and apparent growth in 4-year-old children in the Pacific Islands Family Study. NZ Med J 2008:121:63-71.

10. Rush E, Gao W, Funaki-Tahifote M, et al. Birth weight and growth trajectory to six years in Pacific children. Int $J$ Pediatr Obes 2010;5:192-9.

11. Oliver M, Schluter PJ, Healy GN, et al. Breaks in sedentary timeassociations with body size in Pacific mothers and their children: findings from the Pacific Islands Families Study. J Phys Act Health 2013;10:1166-74.
12. Oliver M, Schluter PJ, Rush E, et al. Physical activity, sedentariness, and body fatness in a sample of 6-year-old Pacific children. Int $J$ Pediatr Obesity 2011;6:e565-e73.

13. Maddison R, Ni Mhurchu C, Jiang Y, et al. International Physical Activity Questionnaire (IPAQ) and New Zealand Physical Activity Questionnaire (NZPAQ): a doubly labelled water validation. Int $J$ Behav Nutr Phys Act 2007:4:62.

14. University of Otago and Ministry of Health. Methodology report for the 2008/09 New Zealand adult nutrition survey. Wellington, New Zealand: Author, 2011.

15. Ministry of Health. NZ food, NZ children. Key results of the 2002 Nationa Children's Nutrition Survey. Wellington: Ministry of Health, 2003.

16. Petersen AC, Crockett L, Richards $\mathrm{M}$, et al. A self-report measure of pubertal status: reliability, validity, and initial norms. J Youth Adolesc 1988:17:117-33.

17. Cole TJ, Flegal KM, Nicholls D, et al. Body mass index cut-offs to define thinness in children and adolescents: international survey. BMJ 2007;335:194.

18. Rush EC, Crowley J, Freitas IF, et al. Validity of hand-to-foot measurement of bioimpedance: standing compared with lying position. Obesity (Silver Spring) 2006;14:252-7.

19. Rush EC, Puniani K, Valencia ME, et al. Estimation of body fatness from body mass index and bioelectrical impedance: comparison of New Zealand European, Maori and Pacific Islands children. Eur J Clin Nutr 2003;57:1394-401.

20. American Thoracic Society. ATS statement: guidelines for the six-minute walk test. Am J Respir Crit Care Med 2002;166:111-17.

21. Castro-Piñero J, Artero EG, España-Romero V, et al. Criterionrelated validity of field-based fitness tests in youth: a systematic review. Br J Sports Med 2010;44:934-43.

22. Newman DG, Pearn J, Barnes A, et al. Norms for hand grip strength. Arch Dis Child 1984;59:453-9.

23. Ozemek C, Kirschner MM, Wilkerson BS, et al. Intermonitor reliability of the GT3X+ accelerometer at hip, wrist and ankle sites during activities of daily living. Physiol Meas 2014;35:129-38.

24. Lee JA, Williams SM, Brown DD, et al. Concurrent validation of the Actigraph gt $3 \mathrm{x}+$, Polar Active accelerometer, Omron HJ-720 and Yamax Digiwalker SW-701 pedometer step counts in laboratory-based and free-living settings. J Sports Sci 2015;33:991-1000.

25. Jarrett $H$, Fitzgerald $L$, Routen AC. Interinstrument reliability of the ActiGraph GT3X+ ambulatory activity monitor during free-living conditions in adults. J Phys Act Health 2015;12:382-7.

26. Cain KL. IPEN Adolescent Accelerometer Scoring Protocol. Secondary IPEN Adolescent Accelerometer Scoring Protocol. 2013. http://www.ipenproject.org/methods accelerometers.html

27. Evenson KR, Catellier DJ, Gill K, et al. Calibration of two objective measures of physical activity for children. J Sports Sci 2008;26:1557-65.

28. Oliver M, Badland HM, Schofield GM, et al. Identification of accelerometer nonwear time and sedentary behavior. Res $Q$ Exerc Sport 2011:82:779-83.

29. Mavoa S. Delineating neighbourhood and exposure in built environment and physical activity research. Massey, 2016.

30. Vandevijvere S, Sushil Z, Exeter DJ, et al. Obesogenic retail food environments around New Zealand schools: a National Study. Am J Prev Med 2016;51:e57-66.

31. Frank LD, Sallis JF, Conway TL, et al. Many pathways from land use to health: associations between neighborhood walkability and active transportation, body mass index, and air quality. J Am Plann Assoc 2006;72:75-87.

32. Badland $\mathrm{H}$, Donovan $\mathrm{P}$, Mavoa $\mathrm{S}$, et al. Assessing neighbourhood destination access for children: development of the NDAI-C audit tool. Environment and Planning B: Planning and Design 2015;42:1148-60.

33. Witten K, Pearce J, Day P. Neighbourhood Destination Accessibility Index: a GIS tool for measuring infrastructure support for neighbourhood physical activity. Environment and Planning A 2011;43:205-23.

34. Badland HM, Keam R, Witten $\mathrm{K}$, et al. Examining public open spaces by neighborhood-level walkability and deprivation. $J$ Phys Act Health 2010;7:818-24.

35. Giles-Corti B, Wood G, Pikora T, et al. School site and the potential to walk to school: the impact of street connectivity and traffic exposure in school neighborhoods. Health Place 2011;17:545-50.

36. Oliver $\mathrm{M}$, Mavoa $\mathrm{S}$, Badland $\mathrm{H}$, et al. Associations between the neighbourhood built environment and out of school physical activity and active travel: an examination from the Kids in the City study. Health Place 2015;36:57-64.

37. Kuczmarski RJ, Ogden CL, Grummer-Strawn LM, et al. CDC growth charts: United States. Adv Data 2000(314):1-27.

38. Office of the Prime Minister's Science Advisory Committee. Improving the Transition: reducing social and psychological morbidity during adolescence: Office of the Prime Minister's Science Advisory Committee, 2011. 